\title{
La noción de patria en el discurso de Unidos Podemos (2016-2017): la articulación de un patriotismo constructivo
}

\section{The notion of homeland in Unidos Podemos discourse (2016-2017): the articulation of a constructive patriotism}

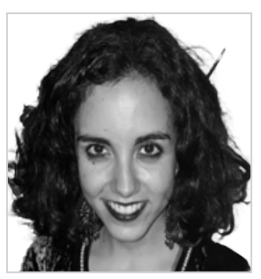

\begin{abstract}
Carmen González Gómez. Graduada en Filología Hispánica por la Universidad de Salamanca, Máster en Lengua Española por la Universidad Autónoma de Madrid, actualmente realizo mi tesis doctoral en la Universidad de Salamanca sobre discurso político español. Mis líneas de investigación son el análisis del discurso y la lingüística cognitiva. Soy autora de diversos artículos sobre lenguaje político, docente a nivel de grado en la Facultad de Filología de la Universidad de Salamanca, y miembro de proyectos de investigación relacionados con la enseñanza del español como lengua extranjera.

Universidad de Salamanca, España

carmen.gonzalez@usal.es

ORCID: 0000-0003-0408-0442
\end{abstract}

Recibido: 23/06/2020 - Aceptado: 24/10/2020

\section{Resumen:}

En el lenguaje político español, la selección léxica empleada para aludir a la nación revela diferencias ideológicas: mientras las formaciones de la derecha se refieren a España, los partidos de corte progresista o nacionalista hablan del Estado español. De igual modo, el término patria se asocia generalmente al imaginario conservador. Desde su irrupción en el panorama político en el año 2014, Podemos ha tratado de resignificar dicho concepto, articulando un patriotismo constructivo opuesto al patriotismo ciego de los conservadores. Para ello, ha intentado vincular la patria a la defensa de los derechos y libertades del pueblo y al estado del bienestar. Este trabajo pretende explicar en qué ha consistido la apropiación del término en el discurso de la formación durante sus dos primeros años de andadura parlamentaria (2016-2017).

Palabras clave:

Patriotismo constructivo; discurso político; Unidos Podemos; patria; marco conceptual.
Received: 23/06/2020 - Accepted:24/10/2020

Abstract:

In the Spanish political language, the lexical selection used to refer to the concept of nation shows striking ideological differences: rightwing parties use the term Spain whereas progressive or nationalist parties favour the phrase Spanish State. Similarly, the term homeland is generally associated with conservative imagery. Since its appearance on the political scene in 2014, Podemos has tried to give a new meaning to the concept of homeland, articulating a constructive patriotism opposed to the blind patriotism of the conservatives. In order to do this, Podemos has tried to link the notion of homeland to the defense of people's rights and freedoms and to the Welfare State. This work aims to explain what the appropriation of the term has consisted of in the discourse of Podemos during its first two years of parliamentary career (2016-2017).

Keywords:

Constructive patriotism; political discourse; Unidos Podemos; homeland; frame.

Cómo citar este artículo:

González Gómez, C. (2020). La noción de patria en el discurso de Unidos Podemos (2016-2017): la articulación de un patriotismo constructivo. Doxa Comunicación, 31, pp. 303-314. 


\section{Introducción}

En el lenguaje político español, la voz patria es un término marcado desde el punto de vista de sus connotaciones. Al igual que los símbolos nacionales, el patriotismo se asocia de manera habitual con el imaginario conservador. Los partidos de corte progresista o nacionalista evitan generalmente referirse a España; emplean en su lugar la construcción Estado español, o rodeos como este país o nuestra nación.

La reticencia no es nueva; en los años treinta del siglo pasado, las formaciones nacionalistas pusieron en boga el término Iberia para evitar así referirse a España (García Santos, 1980: 514). La asimetría está igualmente presente en el discurso político de la Transición; símbolos como el himno o la patria son en este momento patrimonio de la derecha (De Santiago, 1992: 197). También la bandera constitucional es contestada por las fuerzas progresistas: por un lado, porque recuerda demasiado a la de la dictadura, ya que los colores y la disposición son iguales, con la única diferencia del escudo; por otro, porque los nacionalistas catalanes, vascos y gallegos sienten mayor apego hacia sus banderas regionales (Aguilera de Prat y Vernet Llobet, 1993: 150). Todavía hoy, casi un siglo después del final de la Segunda República, una parte del espectro progresista y nacionalista reivindica el legado y la bandera republicana, y muestra rechazo a la oficial, en parte como crítica a la Transición.

Para este sector ideológico, las voces patria o España se asocian con el deseo de uniformidad lingüística y cultural, y con el resabio autoritario de los tiempos de la dictadura o del imperio. Esta vinculación que lleva a cabo una parte de la izquierda de la nación española con valores antidemocráticos explica que el nacionalismo español sea visto como reaccionario, en contraste con los nacionalismos periféricos, que se consideran movimientos progresistas que reivindican de forma legítima el reconocimiento de su nación dentro del estado. Unidos Podemos ${ }^{1}$ defiende, por ejemplo, la plurinacionalidad del estado español al mismo tiempo que critica el discurso nacionalista del Partido Popular o de Vox.

Las causas de que los símbolos de la nación se asocien al bloque conservador son, por tanto, dos: de un lado, el abandono consciente por parte de la izquierda de este imaginario que considera retrógrado; de otro, la apropiación de los conservadores de voces como patria o de elementos como la bandera, empleada, por ejemplo, en manifestaciones en contra del aborto o del matrimonio homosexual.

La posición de Podemos en relación con las nociones de patria y nación españolas ha sido ambigua desde los orígenes. La formación ha criticado que los conservadores elaborasen un discurso nacionalista o intentasen tapar su corrupción "envolviéndose en la bandera", pero al mismo tiempo ha intentado resignificar desde un enfoque progresista el discurso patriótico. En este sentido, la estrategia ha consistido -en consonancia con los postulados de la lingüística cognitiva- no tanto en rebatir el marco mental cuanto en tratar de instaurar uno nuevo (Lakoff, 2008a y 2008b).

Aunque la defensa de la patria y de los símbolos nacionales haya correspondido tradicionalmente a las fuerzas conservadoras, numerosas voces progresistas han pedido desde hace décadas redefinir el concepto y dotarlo de un contenido

1 La formación ha asumido diversos nombres desde su nacimiento en el 2014. En sus orígenes se denominó Podemos; a partir de 2016, Unidos Podemos; y desde el año 2019, Unidas Podemos. Puesto que este trabajo comprende el período 2016-2017 siempre que hablemos del partido nos referiremos a él por el nombre que tenía entonces, esto es, Unidos Podemos. 
social, ligado a la defensa del estado de bienestar. Durante la Transición, el diputado socialista Solé Tura -padre de la Constitución de 1978- pedía terminar con el eufemismo del Estado español y recuperar la voz España:

“España no es una invención, no es un artificio histórico; es una realidad forjada por la historia (...) pero España está ahí y hay que terminar con el eufemismo de designar esto con el nombre de Estado español. (...) España es una realidad multiforme, pero es una realidad y es tarea de todos hacer que, incluso sus propios símbolos sean reconocidos como tales" (citado en De Santiago, 1992: 199).

En la misma línea se manifestaba Peces Barba -exdiputado socialista y padre de la Constitución-en un artículo publicado en El País en el año 2011 cuando contraponía el verdadero patriotismo, "el que debe adornar a los buenos ciudadanos", con el patriotismo rancio y sentimental:

"Se debe descartar el patriotismo rancio y sentimental característico del pensamiento conservador y reaccionario español y también el patriotismo selectivo de un fragmento de Estado, como el que defienden en Cataluña y en el País Vasco los nacionalistas radicales, que no aceptan la idea de una España fundidora e integradora”2.

La distinción descansa en los conceptos propuestos por Staub (1997): blind patriotism (patriotismo ciego) y constructive patriotism (patriotismo constructivo). El primero se caracteriza por apoyar de manera incondicional a la patria y por una lealtad superficial a los símbolos de la nación; el segundo, en cambio, aflora cuando hay una conciencia crítica y un sentimiento identitario de pertenencia a un grupo por el cual se debe velar. En cualquiera de los dos casos se concibe la nación como una comunidad imaginada, en la que la mayoría de los individuos no se conoce ni se conocerá jamás, pero se siente englobada en el mismo proyecto colectivo (Anderson, 1993). El patriotismo ciego, no obstante, es más chovinista, consiste en una exaltación irracional de los símbolos del país y, en este sentido, se identifica más con la postura tradicional del nacionalismo (Olloqui, 2016). El patriotismo constructivo, en cambio, se aleja de esta idea, concibe la comunidad como una asociación de individuos cuyos derechos y libertades se deben salvaguardar (Huddy y Khatib, 2007).

En España, el intento de articular un patriotismo constructivo corresponde a Unidos Podemos. La formación ha tratado de vincular la defensa de la patria con la de los derechos sociales y el estado de bienestar. Esta estrategia ha supuesto un viraje dentro de la tradición política española, donde el campo semántico se asociaba con el discurso conservador.

Según el análisis de Franzé (2017), el intento de apropiación de la noción de patria aparece ya en el 2014. La primera etapa de la formación (20142015) se caracteriza por una impugnación del sistema político heredado de la Constitución de 1978, asociado con las oligarquías, la dictadura y una visión retrógrada del país. Se hace hincapié en este momento en la dicotomía arriba abajo y en la existencia de una clase política y económica que vive ociosa a costa de la clase trabajadora: "la casta".

Este discurso se modera a partir de 2015; el blanco de críticas ya no es el texto constitucional de 1978, sino más bien el sistema neoliberal que amenaza los derechos sociales (Franzé, 2017: 231). Aunque el discurso que elabora la formación ya no es tan contundente, la defensa de la patria y el intento de articular un eje arriba abajo siguen presentes en su an-

2 Disponible en: https://elpais.com/politica/2011/11/10/actualidad/1320951981_599810.html [Última consulta: 16/06/2020]. 
dadura parlamentaria al menos durante los dos primeros años (2016-2017). Los patriotas son aquellos que defienden los derechos sociales del pueblo; los antipatriotas, los que roban y se corrompen, o los que privatizan los servicios públicos.

Este trabajo parte de la hipótesis de que el término patria y sus derivados (patriota, patriotismo, antipatriota) han desempeñado un papel fundamental en el discurso de la formación durante el período 2016-2017. El objetivo es delimitar con qué fin se ha utilizado, a qué valores se han asociado dichas voces y en qué ha consistido, en definitiva, la resignificación propuesta por Unidos Podemos durante los dos primeros años de su trayectoria parlamentaria.

\section{Metodología}

En este estudio se analiza desde un punto de vista cualitativo el discurso político español de Unidos Podemos durante el período 2016-2017, estableciendo como fechas demarcadoras el 30 de agosto de 2016 y el 13 de diciembre de 2017. A partir de los debates parlamentarios se pretende indagar en cómo ha empleado la formación el marco conceptual de patria y conocer qué connotaciones ha intentado vincular a dicho término.

Para el análisis se parte de un corpus constituido por 240 debates parlamentarios correspondientes al período mencionado. La muestra se crea a partir de la selección de los debates más destacados de la legislatura. Abarca, por tanto, todas las discusiones del pleno relevantes desde el punto de vista político, y excluye únicamente aquellas que no presentan un interés discursivo ${ }^{3}$. Esta cala supone una muestra suficientemente representativa del lenguaje político de la formación. Incluye discursos sobre diversas cuestiones (economía, derecho a una vivienda, ecología, feminismo, cuestión territorial, etc.), así como otros debates de carácter más general como son la moción de censura presentada por Unidos Podemos en junio de 2017 contra el gobierno de Rajoy, o el debate sobre los Presupuestos Generales del Estado.

El principal objetivo es describir en qué dominios conceptuales se utiliza el término de patriay con qué fines. Para ello, se pone el foco en tres temas: el conflicto catalán, donde se ha reivindicado el carácter plurinacional de la patria; el terreno económico, donde se ha presentado la corrupción como una conducta antipatriota; y el discurso populista, donde la patria ha servido para apuntalar la dicotomía pueblo-élite.

\section{Análisis y resultados}

La estrategia de la formación morada ha consistido en resignificar el concepto de patria y desvincularlo de sus connotaciones conservadoras. Unidos Podemos se ha presentado como el verdadero garante de los derechos y libertades del pueblo, frente a quienes apelan a la patria y a la bandera en sus discursos pero después gobiernan en contra de sus compatriotas. El patriotismo real consiste en defender los servicios públicos y en proteger a las familias que tienen a sus miembros en paro. A esta defensa del estado del bienestar se contrapone el patriotismo ciego de los conservadores, que se ocupan de extorsionar o criminalizar a sus rivales. Mientras el Partido Popular denomina "policía patriótica" a la unidad

3 Se descartan, por ejemplo, los debates sobre el IVA de los servicios veterinarios o las discusiones sobre la utilización de las redes sociales por parte de los adolescentes, pero se consideran todos los que abordan de alguna manera la cuestión económica y territorial, así como los que atañen a los derechos y libertades civiles (género, derechos LGTBI, memoria histórica, etc.). 
del Ministerio del Interior que se encarga de espiar a otros líderes políticos, Unidos Podemos reivindica unas Fuerzas y Cuerpos de Seguridad del Estado que persigan la corrupción y defiendan la "verdadera patria":

"Para usted el patriotismo tiene que ver con espiar, extorsionar, financiar unidades irregulares de la policía, que filtran informes falsos y sin firmar a los medios de comunicación para criminalizar a fuerzas políticas democráticas, a fuerzas políticas catalanas, pero también a fuerzas políticas españolas. Para nosotros, el patriotismo es otra cosa y lo hemos explicado muchas veces. Para nosotros, el patriotismo es defender los servicios públicos, es proteger a las familias que tienen a todos los miembros en paro, es defender el honor de las instituciones impidiendo que estas se conviertan en una maquinaria de guerra contra los adversarios políticos, porque esa es la única línea roja que separa los Estados de derecho de los Estados en los que se hace el capricho de los que mandan. Si usted sigue insistiendo en que estamos hablando de una policía patriótica, nosotros le tenemos que decir que nos parece un comportamiento profundamente antipatriótico. El comportamiento patriótico de la policía lo demuestran cuando son capaces de investigar las tramas de corrupción, muchas presuntamente vinculadas a su partido, pese a las zancadillas o pese al amparo que se le daba al señor Rodrigo Rato” (Errejón Galván, DS, 27/09/2016, p. 50).

"afirmando que les queremos persiguiendo a sus corruptos y no a personas por sus ideas políticas y afirmando que quienes manchan su nombre -como ha quedado acreditado en esta Comisión- creando estructuras parapoliciales que manchan el nombre de las Fuerzas y Cuerpos de Seguridad del Estado de nuestro país, son unos antipatriotas, que es lo que son ustedes, unos antipatriotas" (Montero Gil, DS, 21/09/2017, p. 25).

Los verdaderos patriotas no son los que elaboran un discurso nacionalista, sino los que defienden una sanidad universal. "Amar a la patria" significa valorar los servicios públicos, defender el estado del bienestar frente a los "antipatriotas" -aquellos que pretenden privatizarlo- y garantizar una educación de calidad y una vivienda digna para todos los ciudadanos.

"Señor Rajoy, a nosotros nos va a tener enfrente en esta legislatura básicamente porque amamos nuestra patria, amamos España y amamos las cosas buenas que hay en nuestro país, porque, efectivamente, en nuestro país hay muchas cosas buenas a pesar de ustedes; y como nosotros, muchos compatriotas que no se sientan en un escaño pero que defienden que haya un sistema público de salud, que defienden que haya un sistema público de educación, que defienden el derecho a la vivienda, que defienden los derechos civiles" (Iglesias Turrión, DS, 27/10/2016, p. 32).

En el terreno económico, Unidos Podemos ha presentado a las fuerzas conservadoras como "antipatriotas": los que enaltecen la patria en sus discursos son los que después actúan en contra del interés general. Los verdaderos patriotas no entregan la soberanía de la nación a los poderes económicos europeos, ni se resignan a las duras condiciones que estos imponen, condenando a países como España a ser la periferia de Europa. Aunque el discurso contra las oligarquías europeas ya no está tan presente como en los orígenes, continúa la crítica hacia los países del norte de la Unión Europea por los sacrificios que demandan a los del sur.

“¡Los defensores de la patria, señorías del Partido Popular! Para mantener este modelo económico extractivo ustedes han tenido que actuar en contra del interés general, y también dejar en papel mojado nuestra Constitución” (Montero Gil, DS, 13/06/2017, p. 11). 
“¿Por qué razón cuando un ciudadano o una ciudadana española tiene un pleito con Google tiene que pleitear bajo la dependencia o los foros de los tribunales norteamericanos? Esta enmienda es muy sensata y nosotros creemos que ustedes, señores patriotas del Partido Popular, deberían defender la soberanía de nuestro país” (Díaz Pérez, DS, 20/06/2017, p. 40).

"No es la imagen de mi patria que yo quiero que se conozca en el extranjero, una imagen vinculada a perogrullos y a cuñadismos, señores del PP. Por último, a propósito de la soberanía -en esto estoy de acuerdo con usted-, el derecho de los ciudadanos de un país a decidir sobre su propio futuro, exactamente lo contrario que hicieron ustedes pactando con este partido la reforma del artículo 135 de la Constitución, entregar la soberanía de nuestra patria" (Iglesias Turrión, DS, 15/03/2017, p. 48).

"El problema es que su modelo político corrupto funciona en la diferencia española, concibiendo nuestra patria como una periferia de Europa” (Iglesias Turrión, DS, 13/06/2017, p. 61).

"Se demostró con la crisis económica, señor Rajoy, que no había unión de transferencia, se demostró que no había ningún federalismo, se demostró que en la Unión Europea nuestra patria España tiene intereses diferentes a los intereses alemanes; y esa es la prueba del fracaso del proyecto político de la Unión Europea” (Iglesias Turrión, DS, 15/03/2017, p. 15).

La formación también pone énfasis en que las élites económicas y la casta política no tienen más patria que su dinero. Aunque en sus discursos ensalcen la figura de España, sus dirigentes tienen cuentas en Suiza o en Panamá. Frente al $p a-$ triotismo ciego de los conservadores, el partido reivindica un patriotismo constructivo, sustentado en la redistribución de la riqueza y en el respeto a los derechos y libertades de la ciudadanía. Los que defienden la marca España de modo chovinista -desde campos de fútbol con la pulsera en la muñeca- no son patriotas. Para Unidos Podemos, España es su clase trabajadora, "la camarera de piso que cobra una limosna por cada habitación que limpia", la pensionista que no llega a final de mes o el joven que trabaja en condiciones precarias.

“Cuando hablamos de pagar impuestos, su patria no es España; su patria es Panamá, señorías” (Montero Gil, DS, 13/06/2017, p. 16).

"no es una moción contra España, es una moción por España y contra el Partido Popular, que es quien está saqueando este país y llevándose el dinero de los españoles a Suiza, a Andorra y a Panamá, que es la patria que más les gusta a ustedes” (Montero Gil, DS, 13/06/2017, p. 33).

“¿Qué es España, señorías? ¿España es una marca? ¿España es el palco de un campo de fútbol donde hay señores con pulseritas con la bandera y cuentas en Suiza? España no es eso, señorías. España es la gente trabajadora que madruga y se esfuerza para sacar a los suyos adelante. España es una camarera de piso con dolores de espalda y que cobra una limosna por cada habitación que limpia (...) España es una teleoperadora que cobra 700 euros al mes, una jubilada que estira la pensión para ayudar a los suyos y que tiene que pagar por su culpa por sus medicamentos" (Iglesias Turrión, DS, 13/06/2017, p. 39).

En relación con la cuestión populista, el dominio conceptual de patria resulta útil para reforzar la oposición pueblo élite. Esta dicotomía está presente en el discurso de Unidos Podemos durante al menos los dos primeros años de trayectoria parlamentaria. La patria es el sentimiento del que se jactan "los señoritos"; los que realmente la defienden son los trabajadores. Las élites económicas no se caracterizan por un "espíritu patriótico", sino que viven a costa del Estado y de la ciudadanía. El gobierno del Partido Popular constituye una "trama de antipatriotas" que favorece deliberadamente los 
intereses de las grandes corporaciones que extorsionan al pueblo. El bloque conservador demuestra, por tanto, un comportamiento "antipopular y vendepatrias" cuando pone a disposición de los fondos buitre las viviendas sociales.

“Quiero recordarle algo que decía ese libro. Lo decía Antonio Machado por la boca de Juan de Mairena a propósito de la idea de patria: La patria es, en España, un sentimiento sencillamente popular del cual suelen jactarse los señoritos” (Iglesias Turrión, DS, 13/06/2017, p. 65).

"Señorías, la historia de las élites españolas no es una historia de emprendimiento, innovación y espíritu patriótico. Por desgracia, la historia del bloque de poder en España es la historia de cómo vivir del Estado y de la ciudadanía" (Iglesias Turrión, DS, 13/06/2017, p. 40).

"Ustedes son la fracción política de una trama de antipatriotas, eso es lo que son ustedes. (Aplausos). Su política económica, señor Hernando, tenía un nombre, Rodrigo Rato, un presunto delincuente, y tiene un símbolo, Bankia; no presuma usted de política económica en el marco de la Unión Europea” (Iglesias Turrión, DS, 15/03/2017, p. 48).

"El problema social con que nos encontramos es que en este país tenemos el 30\% de la vivienda vacía de toda Europa. El problema que tenemos en este país es que los señores del partido antipopular se han dedicado a venderlo a pedazos. Son unos vendepatrias que están vendiendo nuestro país a los fondos buitre (...) Lo están haciendo porque es un negocio para los fondos buitre, y si no díganme qué están haciendo los Blackstone y compañía en este país, quiénes están vendiendo este país a pedazos: los vendepatrias, el partido antipopular" (Mayoral Perales, DS, 20/09/2017, p. 40).

Los vendepatrias son aquellos que "llevan la pulsera en la muñeca" y después no dudan en expoliar el país y en privatizar los recursos públicos. Para Unidos Podemos, tanto el Partido Popular como Ciudadanos acometen reformas laborales que perjudican a la clase trabajadora, legislan en contra de los intereses del pueblo y, por tanto, no están legitimados para enaltecer la patria en sus discursos. En cuanto tienen oportunidad, entregan lo mejor de ella a multimillonarios como Sheldon Adelson para que la saqueen y hagan negocio a su costa.

"Y frente a un saqueo, un expolio de estas características, el Gobierno del Partido Popular, que suele llamarse patriota, que suele llamarse nacionalista, no dijo absolutamente nada, quizás porque estaba ocupado privatizando otros servicios y otras fuentes de recursos públicos, como era AENA, o estaba haciendo reformas laborales, que son las que explican cómo la participación de los salarios en la renta ha ido cayendo cada año de forma sistemática, incrementando de esa forma la explotación sobre la clase trabajadora de nuestro país" (Garzón Espinosa, DS, 14/06/2017, pp. 22 y 23).

"Esto es completamente ilegal y, por supuesto, inconstitucional también; pero no veo ningún patriota, de estos que llevan la banderita en la muñeca y que tienen cuentas en Suiza, por supuesto, poniendo el grito en el cielo. Y yo creo que deberían hacerlo, porque el incumplimiento sistemático de la ley y de la Constitución sí que rompe España, la parte por la mitad" (Rodríguez Rodríguez, DS, 17/10/2017, p. 12).

"De hecho, la actitud suya y la de Ciudadanos me recuerdan esa máxima dicha por un personaje de cuyo nombre no quiero acordarme que decía que, justo cuando la patria se encontraba al borde del abismo, dimos un paso al frente. Y esto es esta PNL, un paso al frente para caer en el abismo" (Domènech Sampere, DS, 19/09/2017, p. 39).

"Lávense la boca antes de hablar de patriotismo, porque ni aman a esta patria ni trabajan por su gente. Y ahora que se han quitado ustedes la careta y que se la ha quitado también su muleta naranja, ya pueden decirlo claro: a ustedes les molestan los derechos sociales; les dan igual los más de dos millones de parados de larga duración que existen en nuestro país, y 
también les da igual que la mitad de los desempleados de nuestro país no tengan ningún ingreso" (Franco Carmona, DS, 28/09/2017, p. 18).

"Pero eso no es ser patriotas, señorías, ¡eso es vender la patria! (Aplausos). Les voy a poner un ejemplo. Uno de los ejemplos más claros de esto fue Eurovegas, donde su colega Ignacio González -que hoy está en la cárcel-prometió a Sheldon Adelson” (Montero Gil, DS, 13/06/2017, p. 12).

Las constantes alusiones a la patria refuerzan el discurso populista de la formación, que se presenta como el único partido comprometido con el pueblo, como el único capaz de defender sus intereses. Sorprenden aquí algunas expresiones como "deberse al honor de la patria". Los representantes se erigen en los protectores de un pueblo que está sometido y al que sus gobernantes no están defendiendo: amar a la patria es "cuidar del pueblo".

"Gracias, señora presidenta, voy concluyendo. Permítame decirle que me debo al honor de mi patria y de los ciudadanos de mi país, no al honor de esta Cámara. (Protestas. -Aplausos-). Va a ser divertido si después algunos diputados exigen turno de palabra por alusiones después de hablar de potenciales delincuentes" (Iglesias Turrión, DS, 27/10/2016, p. 23).

"Hoy no se van a salir con la suya. Hoy, frente al Gobierno del Partido Popular, vamos a hacer patriotismo y vamos a defender a nuestro pueblo" (28/09/2017)

"Estas personas, a las que ustedes no están protegiendo, son mi patria, y ahí está la España que se rompe" (Franco Carmona, DS, 19/10/2017, p. 11).

“Dejen de ser patriotas de pulsera, sean patriotas de corazón, trabajen por solucionar los problemas de este nuestro país. Trabajar por España es trabajar por quienes menos tienen y amar a la patria es cuidar de nuestro pueblo" (Franco Carmona, DS, 19/10/2017, p. 12).

En la misma línea, son habituales las referencias a los compatriotas. Siempre que se apela a ellos se hace para denunciar que vivan en condiciones precarias, que "se hayan caído" de la clase media, que hayan tenido que exiliarse por la falta de empleo o que se vean afectados por el empobrecimiento que suponen las políticas neoliberales. Se utiliza, por tanto, de modo más restrictivo que en el discurso de los conservadores: no tanto para elaborar un discurso nacionalista que englobe al conjunto de españoles, sino para crear una dicotomía arriba abajo que oponga el pueblo -la verdadera patriaa la élite.

"Desde que se aplican políticas de austeridad en España tres millones de compatriotas se han caído de la clase media. ¿ Y ahora nos van a contar que este Gobierno, con Mariano Rajoy al frente, va a ir por un camino diferente?" (Iglesias Turrión, DS, 27/10/2016, p. 22).

“¿Qué barbaridad que en nuestro país haya expresidentes y exministros que se sienten en los consejos de administración de empresas estratégicas que siguen cortando la luz y la calefacción a compatriotas nuestros!” (Iglesias Turrión, DS, 23/11/2016, p. 40).

"Ser ejemplo en el mundo es ocuparse de nuestros compatriotas que se han visto obligados a marcharse y favorecer su regreso para que creen riqueza en nuestra tierra” (Iglesias Turrión, DS, 13/06/2017, p. 60).

"hubo una enorme crisis económica que puso en cuestión el modelo social europeo, fundamentado en políticas neoliberales, que se tradujo en el sufrimiento de buena parte de nuestros compatriotas, en el empobrecimiento de los sectores populares, 
en la pérdida de expectativas de los sectores medios, en desahucios, en paro, en pobreza y en migración" (Iglesias Turrión, DS, 12/12/2017, p. 14).

En la cuestión territorial, también se emplea de manera habitual el concepto de patria. El bloque conservador elabora normalmente un discurso nacionalista para subrayar la indivisibilidad del estado español y para acusar a las fuerzas independentistas de querer dividirlo o romperlo. Asimismo, arremete contra los partidos de corte progresista por no ser leales a la nación y por aliarse con las fuerzas separatistas.

La estrategia de Unidos Podemos consiste en resignificar la idea de patria de acuerdo con sus intereses políticos. La patria no es una ni es indivisible, sino que está integrada por diferentes pueblos soberanos que tienen derecho a decidir si forman parte de ella o no. Cualquier fuerza política que se considere patriota debe asumir la plurinacionalidad del estado. Frente al concepto uniforme de nación que propone el bloque conservador, la formación de Iglesias reivindica la riqueza plurinacional de España y el derecho de todas las naciones que la conforman a decidir si quieren autodeterminarse o no como estados.
"queremos una reforma fiscal para que no se ajuste el cinturón solamente la gente de abajo y se lo ajusten los de arriba también, queremos soluciones democráticas a los problemas que plantea la plurinacionalidad de nuestra patria. Somos muy diferentes" (Iglesias Turrión, DS, 27/10/2016, p. 34).
"La experiencia de Estado de las derechas españolas durante los siglos XIX y XX, desde la Restauración, pasando por la dictadura de Primo de Rivera, por el Bienio Negro o la dictadura franquista, hasta las dos legislaturas de Aznar, configuró una visión estrecha y predominantemente autoritaria de la realidad española en la que ustedes siempre niegan algo evidente, la plurinacionalidad de nuestra patria” (Iglesias Turrión, DS, 13/06/2017, p. 54).
"Esto no solamente es la historia de Cataluña, esto es la historia de España, y un patriota no puede negar la historia de su patria, tiene que conocerla, señorías" (Iglesias Turrión, DS, 13/06/2017, p. 55).
"Del mismo modo que ustedes son vascos, patriotas y se sienten orgullosos, yo soy español y demócrata y estoy orgulloso de mi patria. Le aseguro que este es un gran país que va a cambiar, que va a avanzar contra la corrupción y que va a lograr abrir una vía constituyente para reconocer una cosa fundamental de nuestro país: la plurinacionalidad. Estoy convencido de que podremos encontrar vías de entendimiento, pero entienda que el mismo amor que tiene usted a su patria le tengo yo a la mía” (Iglesias Turrión, DS, 13/06/2017, p. 92).

Además de en la cuestión económica y territorial, el patriotismo constructivo se traslada a otras esferas y se asocia con la protección de la riqueza nacional: en ecología, ser patriota es salvaguardar el patrimonio natural; en cultura, consiste en proteger el legado artístico; en el mundo empresarial, supone apostar por industrializar el país para que no dependa exclusivamente del sector turístico; y en el ámbito feminista, es defender la igualdad entre los dos sexos. La patria es un significante vacío que Unidos Podemos llena a voluntad de acuerdo con su proyecto político. La tarea de un patriota -llega a afirmar Irene Montero durante la moción de censura- es expulsar al gobierno del Partido Popular.

"En las últimas semanas llevamos viendo y escuchando mucho patriotismo de envolverse en banderas y demás. Yo creo que hay un patriotismo real que es el patriotismo de aquellos que están defendiendo, con grandes dificultades, nuestro patrimonio natural” (López de Uralde Garmendia, DS, 07/11/2017, p. 25). 
"Imagino que usted debe saberlo, pero somos el tercer país del mundo en número de bienes culturales considerados Patrimonio de la Humanidad por la Unesco y sorprende el amor y la protección que merece nuestro patrimonio para ser ustedes tan patriotas" (García Sempere, DS, 22/11/2017, p. 42).

"para que nuestra patria pueda presumir de tener una de las industrias más avanzadas de Europa, y no ser el país que exclusivamente puede ofrecer bajos salarios y sol y playa a las clases medias europeas? Ser patriota es apostar por la innovación y por un modelo productivo fuerte" (Iglesias Turrión, DS, 13/06/2017, p. 50).

“El 8 de marzo España, las mujeres españolas demostraron que nuestra patria está en la vanguardia del feminismo” (Iglesias Turrión, DS, 26/06/2018, p.6).

"comprendan que lo que debe hacer un patriota, que lo que debe hacer un demócrata es trabajar incansablemente para echarles a ustedes" (Montero Gil, DS, 13/06/2017, p. 8).

La patria no es un concepto atemporal que se construye desde el presente. Unidos Podemos ha intentado dotarlo de un contenido histórico, vinculándolo con los valores de la Segunda República y con la lucha antifascista de los años treinta del siglo xx. De ahí que afloren términos relacionados con este campo semántico cuando se alude a las brigadas internacionales o cuando se habla de la resistencia política que combatió al fascismo europeo.

\footnotetext{
"Se conmemora en estos días el $80^{\circ}$ aniversario de la llegada a nuestra patria de las brigadas internacionales. A los pocos que quedan vivos y a los que han mantenido la llama de su memoria encendida gracias por venir a nuestra patria a combatir el fascismo" (Iglesias Turrión, DS, 27/10/2016, p. 19).

"Estamos en una época en la que conviene recordar los años treinta, cuando los sistemas liberales europeos entraron en crisis y cuando la amenaza de los fascismos solo se vio superada por una respuesta que se llamó antifascismo europeo, una alianza entre las organizaciones de la clase trabajadora, organizaciones políticas liberales y también por fuerzas políticas patriotas" (Iglesias Turrión, DS, 15/03/2017, p. 15).
}

A lo largo de este trabajo hemos sostenido que el principal cometido de la formación ha sido articular un patriotismo constructivo que se oponga al nacionalismo ciego de los conservadores. No obstante, en el discurso de Unidos Podemos también aparecen exaltaciones a la patria que están más cerca del chovinismo que del patriotismo social. En varias ocasiones, los diputados emplean expresiones como "amar a la patria" o "tener fe en ella". Estas afirmaciones buscan afianzar el nuevo marco conceptual, pero, al mismo tiempo, se sitúan muy cerca del patriotismo ciego que pretenden combatir y corren el riesgo de confundirse con el nacionalismo tradicional que intentan erradicar.

"Discúlpenme, señorías, que me haya extendido buceando en nuestra historia. Sé que no es muy habitual, pero creo que si amas a tu patria debes conocer su historia, porque para cambiar la realidad hay que conocer la historia y la realidad" (Iglesias Turrión, DS, 13/06/2017, p. 44).

“Decía de Cánovas: Causó incalculable mal a la nación. Le hizo perder la fe que le quedaba en lo presente y en lo porvenir. Pocos crímenes menos disculpables que el del hombre que se sitúa al frente de un Gobierno sin fe en la patria. Cánovas era de ese género de políticos: reacio a hacer y mucho menos a pensar en el futuro” (Iglesias Turrión, DS, 13/06/2017, p. 41).

"Sientan vergüenza democrática y, así, sentirán lo mismo que sienten los españoles, que sentimos los españoles y las españolas, que amamos a nuestra patria, cuando les vemos a ustedes hacer lo que hacen" (Montero Gil, DS, 21/09/2017, p. 26). 
Después de todo lo expuesto, cabe preguntarse si estos intentos de apropiación del marco conceptual de patria pueden dar o no sus frutos. Existen razones para pensar que sí, ya que el único modo de cambiar la mentalidad de los electores a largo plazo es instaurar nuevos moldes mentales que ofrezcan una percepción alternativa de la realidad. También existen motivos para creer que no sucederá, debido a lo arraigada que está la simbología nacional en el imaginario conservador y a la reticencia del electorado progresista a asumir el discurso nacionalista.

\section{Conclusiones}

Este artículo ha analizado el discurso de Unidos Podemos durante sus dos primeros años de trayectoria parlamentaria. La formación ha intentado resignificar el concepto de patria desvinculándolo de las connotaciones conservadoras que ha acumulado hasta el momento. De acuerdo con este enfoque, los verdaderos patriotas no son quienes elaboran un discurso nacionalista, sino los que defienden los servicios públicos del estado del bienestar y los derechos y libertades de la ciudadanía.

Esta noción se emplea en diversos debates y con distintos fines: en el terreno económico, para acusar a las élites oligarcas de su conducta y de su doble moral respecto a la patria; en la cuestión territorial, para defender la riqueza plurinacional del estado y el derecho a la autodeterminación de las naciones que la integran; en el imaginario populista, para reforzar la oposición entre el pueblo, el que encarna los verdaderos valores de la patria, y "los de arriba", los que la traicionan. Asimismo, también se utiliza para criticar la corrupción del Partido Popular y las maniobras de espionaje del Ministerio del Interior, o para realizar alegatos a favor del patrimonio cultural y ecológico.

Aunque en la mayoría de las ocasiones el patriotismo del que se ha hace alarde es constructivo -esto es, lleno de contenido social-, en otros casos las exaltaciones de la patria resultan más bien superficiales o chovinistas. Se intenta con ellas desligar por todos los medios la defensa de la patria del discurso conservador. Solo el tiempo dirá si esta apropiación ha logrado instaurar un nuevo marco conceptual o si el patriotismo continúa entendiéndose como patrimonio político de la derecha española. 


\section{Referencias bibliográficas}

Aguilera de Prat, C. y Vernet Llobet, J. (1993). “Cuestiones simbólicas y Constitución española”, Revista de Estudios Políticos, 79, 139-160.

Anderson, B. (1993). Comunidades imaginadas. Reflexiones sobre el origen y la difusión del nacionalismo. México: Fondo de Cultura Económica.

De Santiago Guervós, J. (1992). El léxico político de la transición española. Salamanca: Ediciones Universidad de Salamanca.

Franzé, J. (2017). "La trayectoria del discurso de Podemos: del antagonismo al agonismo", Revista Española de Ciencia Política, 44, 219-246.

García Santos, J. F. (1980). Léxico y política de la segunda república española. Salamanca: Ediciones Universidad de Salamanca.

Huddy, L. y Khatib, N. (2007). "American patriotism, national identity and political involvement", American Journal of Political Science, 51, 63-77.

Lakoff, G. (2008a). The political mind. A Cognitive Scientist's Guide to Your Brain and Its Politics. Nueva York/Toronto/ Ontario/Dublín/Nueva Delhi: Penguin Group.

Lakoff, G. (2008b [2006]). Puntos de reflexión. Manual del progresista. Barcelona: Ediciones Península.

Olloqui, J. (2016). "La patria en el discurso de político de Pablo Iglesias: la construcción del concepto de patriotismo constructivo a partir del lenguaje metafórico”, Cuadernos de Investigación Filológica, 42, 173-205. DOI: 10.18172/cif.3014 Staub, E. (1997). Blind versus constructive patriotism: Moving from embeddedness in the group to critical loyalty and action. En D. Bar-Tal y E. Staub (eds.), Nelson-Hall series in psychology. Patriotism: In the lives of individuals and nations (pp. 213228). Chicago: Nelson-Hall Publishers. 